\title{
El discurso directivo en la comunicación de los estados financieros El caso de dos empresas chilenas
}

Sandra Alvear Vega Universidad de Talca salvear@utalca.cl

José Tello Ávila Universidad de Talca jtello@utalca.cl

\section{Resumen}

El rol de portavoz que desempeñan los directivos de las empresas es objeto recurrente de estudio; en dicho contexto, el discurso directivo (oral o escrito) es considerado una herramienta de gestión. Así, el objetivo de este trabajo es identificar, describir y comprender la función del discurso directivo expresado en la carta de presentación de los estados financieros de las empresas Corporación Nacional del Cobre (Codelco) y Compañía Manufacturera de Papeles y Cartones, S.A. (CMPC), en el periodo 2005-2009. La metodología empleada se basa en el análisis transversal del discurso expuesto en las cartas, a través de la identificación lexical de los enunciados. Del análisis realizado, se infiere que los directivos de las respectivas empresas buscan alinear los resultados económico-financieros obtenidos con el contexto que la empresa enfrenta, esperando ejercer influencia en la construcción de sentido de los integrantes de ciertos grupos de presión social. Paralelamente, se infieren dos dimensiones del discurso directivo: la primera de ellas es estratégica y se expresa en la difusión de una imagen deseada de las empresas en estudio; la segunda de ellas es de marketing, es decir, enfocada en la promoción de la empresa como un "producto" frente a sus "clientes", rol que es asumido por los "accionistas".

Palabras clave: discurso directivo, contabilidad, análisis del discurso 


\title{
The managerial discourse in the communication of financial statements. The case of two chilean companies
}

\begin{abstract}
The role of spokesperson played by company executives is a recurring object of study. In this context, the managerial discourse (either oral or written), is considered a management tool. The aim of this article is to identify, describe and understand the function of the managerial discourse as expressed in the letter of presentation of the financial statements of the companies Corporación Nacional del Cobre (Codelco) and Compañía Manufacturera de Papeles y Cartones, S.A. (CMPC), during the 2005-2009 period. The methodology used is based on the cross-sectional analysis of the discourse exposed in the letters, through the lexical identification of the statements. From the analysis performed, it can be inferred that the managers of the respective companies seek to align economic-financial outcomes obtained with the context which the company faces, hoping to exert influence in the building of sense on the members of some pressure groups. In parallel, two dimensions of managerial discourse are inferred: the first one is strategic, expressed in the dissemination of a desired image of the companies in the study; the second dimension is about marketing, i.e., focused on the promotion of the company as a "product" to their "clients", a role that is assumed by the "shareholder".
\end{abstract}

Keywords: managerial discourse, accounting, analysis of the discourse

\section{Introducción}

A partir de los sesenta, las empresas han sufrido distintas crisis de credibilidad debido a los procesos de democratización, al empoderamiento de los individuos y de los grupos sociales, así como a la evolución de las técnicas de comunicación. Lo anterior ha sido un factor determinante en la formación de diferentes movimientos sociales. Por ello, las empresas, se han visto obligadas a crear estrategias de comunicación distintas, las cuales buscan la aprobación de los distintos grupos de poder que participan de su entorno social.

La contabilidad - como disciplina científica - nació como una necesidad social de medición de la realidad económica al cuantificar las transacciones que realizan las organizaciones. Conforme ha pasado el tiempo, se ha ido adaptando a las nuevas necesidades de información de los usuarios de la información contable; por ejemplo, la incorporación del valor razonable como método de medición (Gómez, De la Hoz 
y López; 2011). No obstante, los directivos de las empresas han entendido que la información cuantitativa no es suficiente para comunicar sus resultados en su calidad de entidad social, sino que también es importante incorporar aspectos cualitativos.

Cada año las empresas presentan sus estados financieros con el fin de comunicar los resultados obtenidos durante ese periodo para facilitar la toma de decisiones de los diferentes usuarios, sean internos o externos) de la información contable. Dichos reportes son publicados en formato de una memoria anual que se inicia con una carta de presentación, firmada por el o los directivos (presidentes de directorio) de las respectivas empresas.

El objetivo de este trabajo es identificar, describir y comprender la función del discurso directivo expresado en la carta de presentación de los estados Financieros de las empresas Corporación Nacional del Cobre (Codelco) y Compañía Manufacturera de Papeles y Cartones, S.A. (CMPC) en el periodo 2005-2009. Las empresas que forman parte de la presente investigación se dedican a la producción de bienes commodities; la diferencia entre ellas radica en que una es una empresa estatal, mientras que la otra es de capitales privados, preferentemente chilenos. Codelco es una empresa pública y principal productor de cobre; en 2011 alcanzó el 31\% del total de la producción nacional y en el mismo año la producción de cobre representó el $11 \%$ del total mundial (Codelco, 2012). Por su parte, CMPC es una empresa privada que participa de la industria de productos forestales; es la segunda mayor productora de celulosa en Chile y la cuarta mayor productora en el nivel internacional (CMPC, 2012).

Es importante precisar que la investigación realizada, esencialmente, se interesa en la perspectiva de la persuasión de los enunciados y no en los efectos obtenidos. La significación de los contenidos existe independientemente de los efectos que ellos tengan. La problemática de la recepción no forma parte de nuestra investigación.

\section{Materiales y métodos}

Los datos de la investigación están formados por los enunciados de las cartas de presentación de los estados financieros anuales de las empresas Codelco y CMPC, emitidas entre 2005 y 2009. A través del análisis transversal del discurso, se examinan los enunciados de las cartas de presentación de los estados financieros, a partir de una propuesta metodológica, basada en la identificación lexical (Alvear; 2011). Este análisis se ocupa de la dimensión interactiva e intersubjetiva del uso 
del lenguaje, mediante la investigación y el análisis de datos reales. Se investiga la lengua escrita, más allá de los límites de la oración, estableciendo la relación entre lengua y sociedad (Pilleux; 2001).

El enfoque es interpretativo, es decir, concibe a la organización como un mundo subjetivo y se interesa en las representaciones de los actores (Girous y Marroquin, 2005). El discurso expuesto en dichas cartas se entiende como una polifonía; en otras palabras, no solamente es interesante por su contenido, sino también por el efecto que se busca producir, construir socialmente la realidad (Berger, Luckmann; 1967). Toda realidad es representada, es decir, apropiada por los individuos o los grupos, reconstruida en su sistema cognitivo, integrada en su sistema de valores, dependiendo de su historia y del contexto social e ideológico que enfrentan. (Rivière; 2006).

El concepto de discurso e influencia son dos conceptos fuertemente relacionados; hablar es, sin duda, un intercambio de información, pero también es un acto regido por reglas precisas que pretenden transformar la situación del receptor y modificar su sistema de creencias y/o cambiar su sistema de actitudes (Kerbrat-Orecchioni, 1980). Un discurso no sólo describe la realidad preexistente, sino que también construye la representación de la realidad que el locutor desea compartir con su interlocutor (Ducrot, 1991). En general, para la mayoría de los especialistas en lenguaje, la emisión de un discurso (oral o escrito) conlleva la intencionalidad de actuar sobre otros.

Las empresas buscan influir y controlar la organización a través de su discurso y la construcción de sentido (sensemaking) (Weick, 1995). La comunicación es vista como el núcleo de la organización y de su entorno; a través de las prácticas discursivas sus miembros se comprometen en la construcción de un sistema complejo con diversos significados (Giroux y Marroquin, 2005). En ese mismo sentido, Chekkar y Onnée (2006) muestran que la evolución del discurso organizacional es fuertemente estructurada por su contexto de enunciación, es decir, para que el contenido de un discurso sea comunicable es necesario compartir ciertas presunciones culturales.

Los actos de lenguaje son influidos por el contexto en el cual la persona que comunica se desarrolla y que también contribuye a construir; es creador de una realidad social que él desea compartir, por lo que se mueve por sus propias representaciones (Seignour, 2011). Del mismo modo, Rivière (2006) muestra que el discurso es una herramienta de co-construcción de la identidad organizacional. 
El análisis de los datos se realiza según una perspectiva interpretativa, es decir, la narración es un reflejo de la cultura. Por ello nos apoyaremos en el análisis del discurso escrito teniendo presente tres dimensiones implícitas en él: social, cognitiva y discursiva. La comprensión del discurso escrito es un fenómeno psicodiscursivo, de naturaleza tanto social como cognitiva. En su dimensión social, la comprensión constituye una actividad comunicativa situada. En cuanto a su naturaleza cognitiva, la comprensión del discurso constituye un proceso intencionado de alta complejidad, conformado por una serie de procesos psicolinguísticos sustentados a la vez en procesamientos cognitivos de orden inferior (atención, percepción y memoria) y superior (toma de decisiones, monitoreo, reflexión, entre otros) (Ibañez, 2012). A continuación se presenta la metodología de análisis empleada.

\section{Contexto social y discursivo del documento}

El contexto se define como el conjunto de condiciones de producción extralingüísticas de una situación discursiva y es determinante para comprender un enunciado. Los actos de lenguaje deben ser comprendidos en su contexto de enunciación (Charaudeau, 2002). Para Gadamer (1998), el dominio técnico de la capacidad de hablar y comprender se manifiesta plenamente en la escritura, en la redacción del discurso y en la comprensión de lo escrito; es una de las relaciones que el autor establece entre retórica y hermenéutica. Dicho contexto es analizado desde el punto de vista social y discursivo a partir del planteamiento de tres preguntas: ¿quién escribe?, ¿a quién se dirige?, ¿qué relación se establece? (ver cuadro 1).

\section{Cuadro 1}

\section{Dimensión social y discursiva de las cartas}

\begin{tabular}{l|l|l|l}
\hline Preguntas de investigación & \multicolumn{2}{|c}{ Social } & \multicolumn{2}{c}{ Discursivo } \\
\hline ¿Quién escribe? & Locutor & Enunciador & Singular, Plural y Neutro \\
\hline ¿A quién se dirige? & Receptor & Destinatario & Singular, Plural y Neutro \\
\hline ¿Qué relación se establece? & Simétrica y Asimétrica & \multicolumn{2}{|c}{ Asertivo, Interrogativo, Intimidador } \\
\hline
\end{tabular}

Elaboración a partir de Alvear (2011).

La semiótica lingüística define un acto de lenguaje como una puesta en escena que coloca en relación dos espacios de significación: el primero (de hacer) externo o situacional, que se define como el espacio que ocupan los responsables de dichos actos; el segundo (de decir) interno o de discurso, que se define como el lugar de la instancia discursiva. La figura social presupone la existencia de la figura discursiva y viceversa (Charaudeau, 1982). 
En la dimensión social se identifica a las figuras de locutor y receptor en una relación simétrica/asimétrica. Luego, en la dimensión discursiva, se identifica la figura del enunciador y destinatario en una relación asertiva/interrogativa/intimidador. El enunciador construye mentalmente el destinatario que, a su vez, establece relaciones cognitivas distintas a las establecidas por el enunciador. Por lo tanto, discursivamente aparecen dos figuras distintas: el sujeto destinatario y el sujeto interpretador (Bruner, 1991).

\section{Análisis de la comunicación}

El objetivo es identificar la estructura argumentativa, desde el punto de vista cognitivo y discursivo, a partir de dos preguntas: ¿en función de qué se comunica?, ¿a partir de qué se comunica? Con la primera pregunta se pretende lograr el marco interpretativo del enunciador (presuposiciones) y a partir de la segunda pregunta la concepción de la realidad a partir de la cual se comunica (ver cuadro 2).

Las actividades de comunicación se realizan en función de las influencias que el enunciador ha recibido, en términos de "decir" oral o escrito y de las relaciones que él hace con otros eventos o espacios de actividad (Bruner, 1986). Luego, se comunican a partir de la concepción (mental) de los distintos espacios de acción que poseemos o de la concepción de la acción realizada por otros individuos, más aún de la proyección de dicha acción. Finalmente, es una manera particular de representación de ciertos eventos.

\section{Cuadro 2}

\section{Análisis de la comunicación}

\begin{tabular}{c|c}
\hline \multicolumn{1}{c|}{ Preguntas } & Dimensión cognitiva y discursiva \\
\hline ¿En función de qué se comunica? & $\begin{array}{c}\text { Marco interpretativo base, que permite al enunciador } \\
\text { presuponer los hechos. }\end{array}$ \\
\hline ¿A partir de qué se comunica? & Concepción del entorno empresarial y de su relación con él. \\
\hline
\end{tabular}

Elaboración a partir de Alvear (2011).

\section{Función de la comunicación}

Los directivos, en su calidad de representante de la organización, son un canal frente a la empresa y su entorno. A través de un acto de comunicación (oral o escrito) ellos proponen distintas formas para observar dicho entorno y la actividad 
realizada por la empresa. Un acto de lenguaje es producto de seres psicosociales que son testigos, más o menos conscientes, de las prácticas y de las representaciones imaginarias de la comunidad a la cual pertenecen y el sujeto, al producir un acto de lenguaje, lo hace para influir sobre otros (Charaudeau y Maingueneau, 2002). El objetivo es identificar el rol de la comunicación presentada en las cartas de presentación de los estados financieros, cómo se propone observar la actividad empresarial y cuál es el impacto en su entorno.

\section{Resultados y discusión}

\section{Contexto social y discursivo de los documentos.}

Del análisis de contenido de las cartas de directorio emitidas entre los años 2005 y 2009 se infiere que la figura social predominante como locutor es el presidente del directorio, le sigue la figura de gerente general (ver figura 1). Según se señala en los estatutos corporativos de Codelco, el gerente general tiene las facultades que el directorio le delegue y permanece en el cargo mientras tenga la confianza de este cuerpo colegiado. Entre los años 2005 y 2009 , se desempeñaron tres profesionales en el cargo de presidente del directorio, dos de ellos ingenieros civiles y el tercero periodista. Asimismo, se desempeñaron dos gerentes generales, uno de ellos de ingeniero comercial y el segundo de economista.

La figura de enunciador se presenta en forma plural, predominantemente a través de un nosotros, seguido de una presentación singular expresada como un yo y de una presentación neutra (ver figura 1). El hecho de que los directivos de Codelco se presenten preferentemente en forma plural expresa que en su discurso asumen una identidad colectiva; es decir, al comunicarse incluyen o evocan a varias personas de la empresa. Esta identidad permite tanto al enunciador como al destinatario presentarse en forma comprometida con lo que se está comunicando. En las cartas se puede leer: "Entre los principales desafíos que tenemos el año 2010, están el asegurar un adecuado avance de los proyectos estructurales... Adicionalmente, debemos seguir mejorando nuestra competitividad" (Codelco, 2009). 


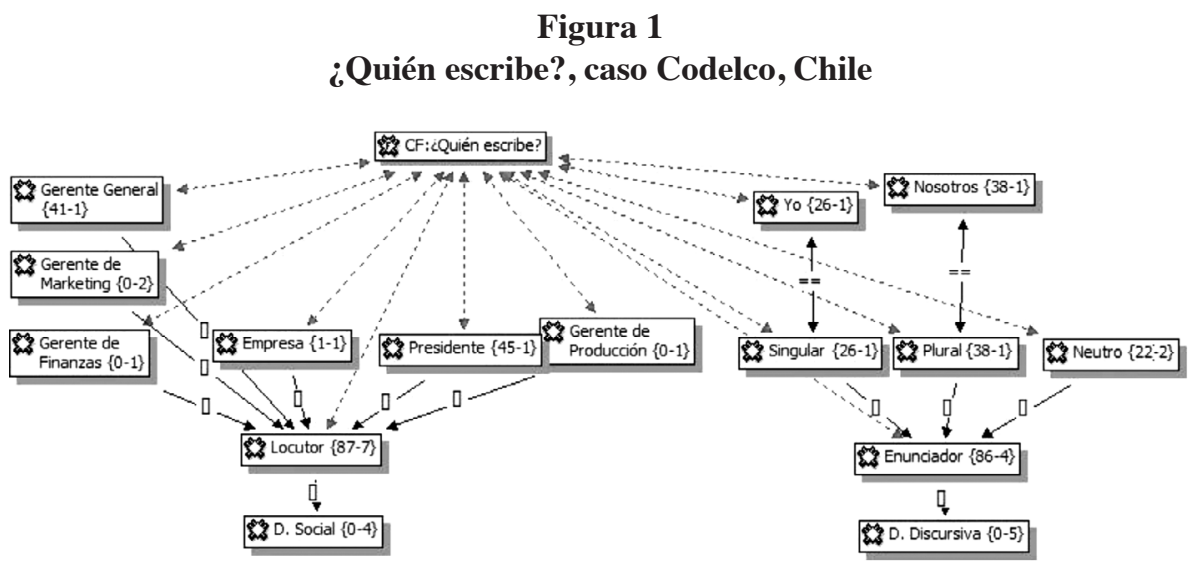

Elaboración propia a partir de resultados obtenidos en la investigación.

Para el caso de CMPC, la figura social predominante (locutor) es la del presidente del directorio, cuya función está regulada por ley 18.046 sobre Sociedades Anónimas. Entre los años 2005 y 2009, el presidente - de profesión ingeniero civil industrial- se mantuvo en su cargo (ver figura 2). Desde el punto de vista discursivo, el enunciador se presenta preferentemente en primera persona singular, yo, que asume una identidad individual, es decir, se presenta de manera subjetiva, sincera e íntima. El yo discursivo se construye mientras se está escribiendo e implica la identificación con determinados discursos sociales y en muchas ocasiones se produce en forma implícita (Castelló et al., 2011). Desde el punto de vista organizacional se muestra a un directivo comprometido, que se adhiere a un discurso institucional. 
Figura 2

¿Quién escribe?, caso CMPC

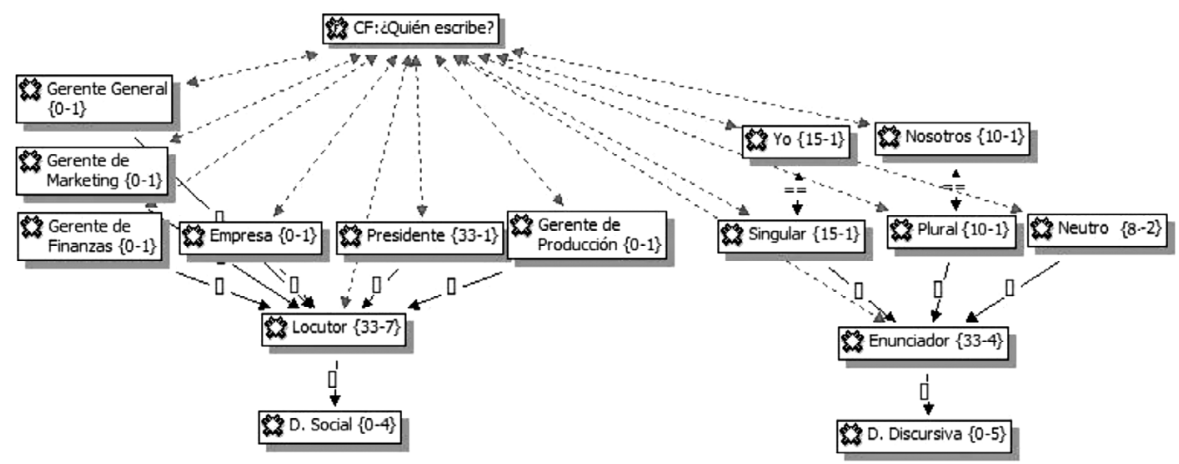

Elaboración propia a partir de resultados obtenidos en la investigación.

Desde el punto de vista social, el locutor se dirige a la figura del receptor. Para el caso de Codelco dicha figura social se centra en los trabajadores, seguida de los chilenos (ver figura 3). En las cartas se puede leer: "Pusimos en práctica un modelo integral de desarrollo de las personas que ofrece a todos los trabajadores la oportunidad de adquirir las competencias que, junto a su desempeño individual, les abren amplios horizontes de crecimiento y progreso personal. Perseveramos en nuestro compromiso por mejorar las condiciones ambientales y de seguridad de nuestras instalaciones y de las comunidades que nos acogen" (Codelco, 2005).

El sujeto destinatario del acto de comunicación es construido por el enunciador; se puede decir que dicho sujeto es construido sobre la base de una estrategia, según los efectos que la figura del enunciador busca producir en el destinatario. En las cartas se puede leer: "Sin embargo, la gestión de Codelco en 2007 no estuvo exenta de dificultades y desafíos. El más importante de ellos es el tema de la seguridad [...]. Para el Directorio y la Administración de Codelco, la seguridad de los trabajadores es la primera prioridad y estamos decididamente comprometidos con todas las acciones necesarias para enfrentar este grave problema" (Codelco, 2007).

Los trabajadores de Codelco - en el contexto de "organización sindical" - son un grupo de presión social importante para la empresa dado el poder de negociación que tienen cada año para lograr acuerdos a través de las negociaciones colectivas; por ejemplo, participación de utilidades a través de la figura de bono de produc- 
ción. El no acceder a las demandas de los trabajadores implicaría eventualmente paralización de faenas, disminución de las metas de producción y aumentos en los costos de producción.

Los directivos de Codelco, a través de los enunciados de las cartas de publicación de los estados financieros, muestran empatía con las demandas de los trabajadores, pero también explicitan los esfuerzos que realiza la empresa con el resto de los chilenos para cumplir con sus demandas. Por está razón, se deben mantener buenas relaciones con ellos para poder producir y así entregar beneficios a todos los chilenos; por ello, en segundo lugar se encuentran estos receptores debido a que la empresa al ser estatal pertenece a todos los chilenos. Por ejemplo, en las cartas se puede leer: "Desde la Presidencia del Directorio de Codelco, he tenido la oportunidad de conocer, de primera fuente, las informaciones más relevantes sobre la Corporación. Basado en lo anterior, me asiste la convicción de que el funcionamiento de la empresa avanzó en el sentido correcto, que ha cumplido con sus metas sumando valor y aportando recursos, y que, por lo mismo, su pertenencia a todos los chilenos y chilenas está más que justificada" (Codelco, 2005).

Podemos inferir que desde el punto de vista de la teoría polifónica del discurso se habla de estrategias discursivas (Ducrot, 1984). Desde el punto de vista discursivo, el enunciador se dirige al destinatario que se expresa en términos plural a través de un ustedes. Con excepción del año 2006, en donde la figura que pasa a predominar es el neutro. Es importante mencionar que en el año 2006 la presidente del directorio de Codelco es periodista. La figura neutra implica marcar discursivamente distancia frente a su destinatario (ver figura 3 ).

Sin duda, los directivos de Codelco y CMPC en su rol de locutor y enunciador de las cartas establecen un contexto de interpretación de los estados financieros a partir de sus enunciados. Es decir, si el locutor hace referencia a un objeto determinado, indirectamente, él está ejerciendo influencia sobre su interlocutor. Cuando las personas hablan, transmiten información para interactuar con otras; finalmente están realizando una acción. En palabras de Austin (1970) "un decir, es un hacer"; según el autor, ciertos enunciados no son simples afirmaciones, sino que son acciones. 
Figura 3

¿A quién se dirige?, caso Codelco, Chile

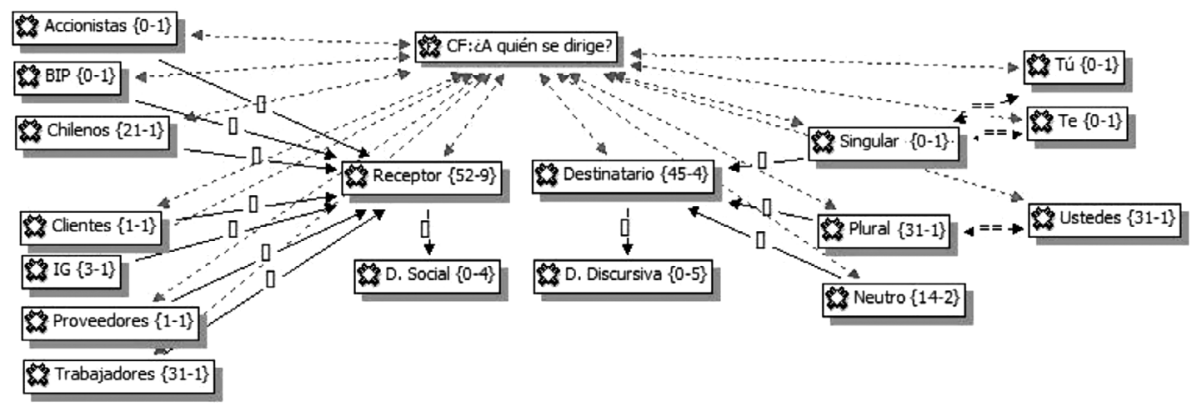

Elaboración propia a partir de resultados obtenidos en la investigación.

Para el caso de la empresa CMPC, el locutor se dirige principalmente a la figura social de accionista, luego a los trabajadores. En las cartas se puede leer: "El año 2006 presentó un entorno macroeconómico complejo y desafiante para CMPC [...]. La economía chilena tuvo un desempeño relativamente débil, considerando el positivo entorno internacional, lo que unido a la fuerte competencia en algunos segmentos del mercado interno, afectó negativamente los resultados de la Compañía” (CMPC, 2006). Se puede desprender que la disminución de los resultados de la empresa tiene un responsable, la economía chilena, un evento externo que está fuera del control de la empresa.

Desde el punto de vista discursivo, el enunciador se dirige a un destinatario predominantemente plural, expresado en ustedes, es decir, se compromete a la figura destinatario. También aparece la figura del destinatario como neutra; en tal caso, el enunciador toma distancia del destinatario, es decir, no se involucra (ver figura 4). 


\section{Figura 4}

\section{¿A quién se dirige?, caso CMPC}

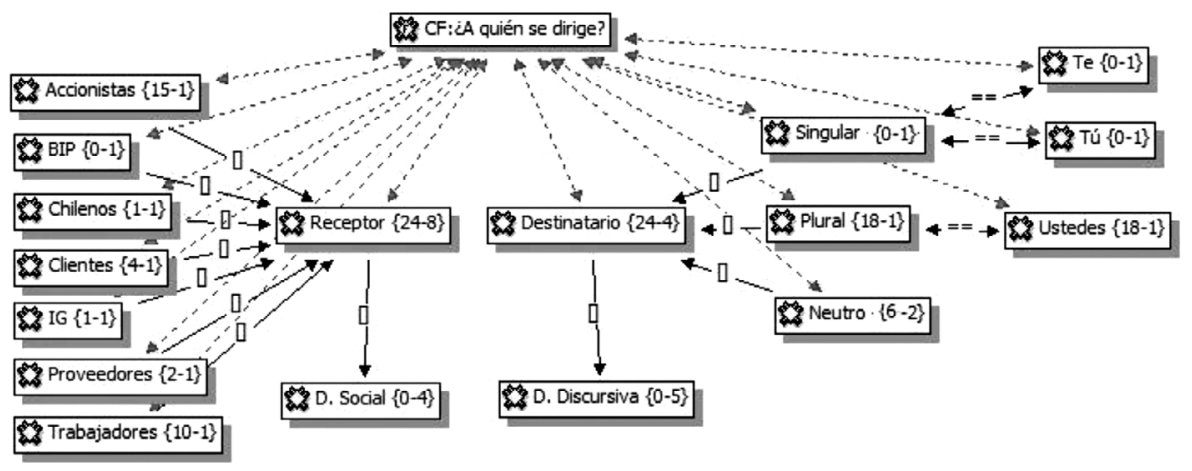

Elaboración propia a partir de resultados obtenidos en la investigación.

Las relaciones de poder forman parte de un acto de comunicación y reflejan el grado de cercanía o lejanía con el público objetivo sobre la base del tipo de relación que el enunciador desea establecer con el destinatario. (Watzlawick, Beavin y Jacksondon, 1972). Desde el punto de vista social se establece en términos simétrico o asimétrico y desde el punto de vista discusivo en términos asertivo, interrogativo o intimidador. Para el caso de Codelco, el presidente del directorio o gerente general establecen preferentemente con su público objetivo (trabajadores y chilenos) una relación simétrica; desde el punto de vista discursivo, se establece una relación asertiva, entre enunciador y destinatario (ver figura 5).

Un discurso asertivo permite al enunciador presentarse con certitud y autoridad, lo anterior no significa que los enunciados que se presentan en las cartas representen la verdad; no obstante, se ofrecen con seguridad y conocimiento, usando palabras que intentan persuadir al destinatario sobre lo que se trata de decir o hacer. En las cartas se puede leer: "La principal empresa de Chile debe ser líder en todos los aspectos, por el bien de Chile". (Codelco, Carta, 2005). 


\section{Figura 5}

\section{¿Qué relación se establece?, caso Codelco, Chile}

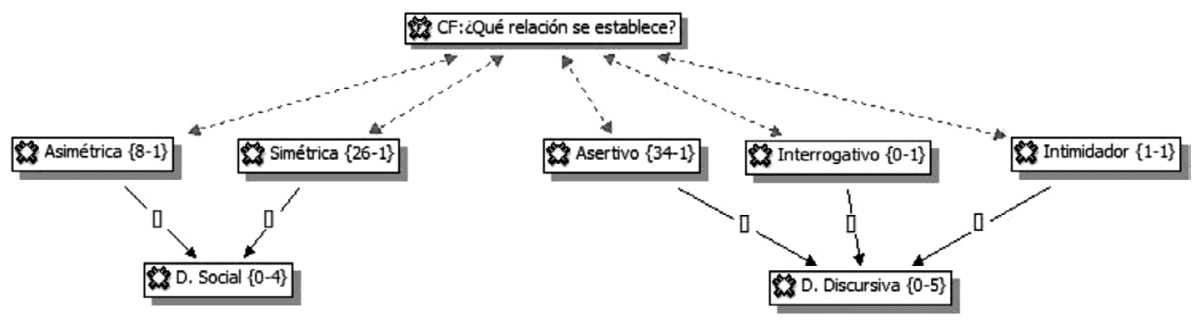

Elaboración propia a partir de resultados obtenidos en la investigación.

En la empresa CMPC, el presidente del directorio establece preferentemente con su público objetivo (accionistas y trabajadores) una relación asimétrica; desde el punto de vista discursivo, se establece una relación asertiva, entre enunciador y destinatario (ver figura 6). En las cartas se puede leer: "Al concluir esta cuenta quisiera agradecer a todos nuestros clientes y proveedores por su preferencia y lealtad; a todas las personas que trabajan en la Compañía por su compromiso, dedicación y esfuerzo en el cumplimiento de sus responsabilidades; y finalmente, a nuestros accionistas por la permanente confianza depositada en nuestra institución". (CMPC, 2007).

\section{Figura 6}

\section{¿Qué relación se establece?, caso CMCP}

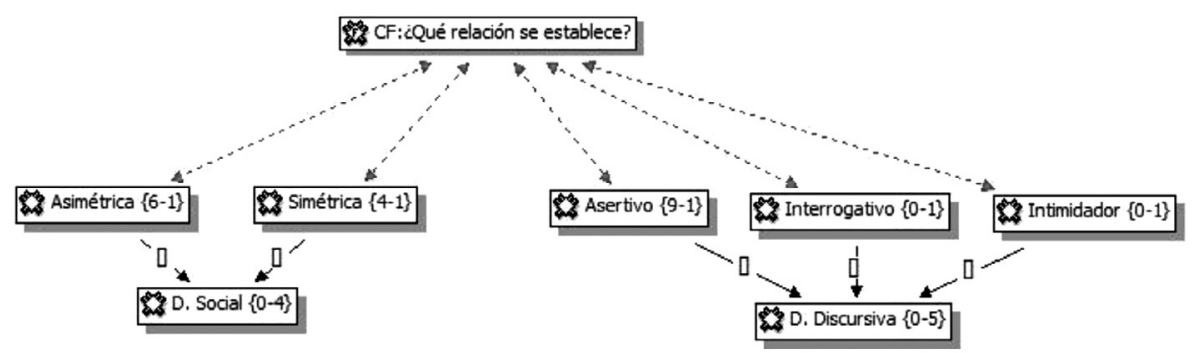

Elaboración propia a partir de resultados obtenidos en la investigación.

\section{Análisis de la comunicación}

Los directivos de Codelco desarrollan su mensaje en función de la realidad empresarial que ellos mismos han contribuido a construir, lo que constituye su memoria 
colectiva (Bruner, 2002) dado que la contribución de esta organización al desarrollo nacional es un tema que está instalado en la sociedad chilena; los directivos lo saben y lo explicitan en las cartas de comunicación de los estados financieros, pues se puede leer frases como "Chile ve con optimismo el futuro de CODELCO, el cual está íntimamente ligado al futuro de Chile" (Codelco, 2009). No es Chile el que realiza dicha presuposición, sino los Directivos de Codelco. Así, podemos afirmar que el presidente del directorio y/o gerente general comunican en función de las representaciones que ellos tienen de una empresa pública como Codelco, conformando de esta forma su marco interpretativo. Lo anterior, se complementa con el rol que ejercen los directivos de una organización, entre otros, promover su imagen, portavoz frente a su entorno e influir en dicho entorno a través de su discurso para obtener relaciones de largo plazo con valor agregado (El-Meligi, 2007).

Los directivos comunican a partir de la concepción que ellos tienen de Codelco, empresa que participa de un hito histórico y es socialmente responsable (ver figura 7). En 2010 se celebra el bicentenario del estado de Chile, lo que para los ejecutivos se convirtió en un hito histórico. En las cartas se encuentran frases tales como "CODELCO seguirá potenciando su contribución al desarrollo de Chile. Esa es la gran tarea de esta década, que se inicia con la celebración del Bicentenario de nuestra Independencia" (Codelco, 2009). La alusión al bicentenario es una forma de comunicar y precisar el rol que ha tenido Codelco como empresa pública en el desarrollo del país, a través de la generación de excedentes y la que aporta los mayores ingresos al presupuesto de la nación. No obstante, el concepto de hito histórico no se encuentra presente en la empresa CMPC.

El concepto de empresa responsable es una concepción base de los ejecutivos en su discurso. Dicha concepción se infiere a partir de la referencia a las distintas acciones que los ejecutivos dicen que la empresa realiza, desde el punto de vista social, cultural, económico, ambiental y laboral. La presuposiciones emitidas se enmarcan principalmente en la dimensión de recursos humanos (18\%), luego en la dimensión ambiental (16\%) y por último en la dimensión económica (13\%) (ver figura 7).

Del análisis de la comunicación financiera se puede inferir que el discurso de los ejecutivos, el cual acompaña la presentación de los estados financieros de Codelco, tiene un enfoque preferentemente nacional, pues destaca su contribución en el desarrollo del país; asimismo, es una empresa socialmente responsable que se involucra y establece un lugar en la historia país. Por último, se crea una relación 
con la dimensión estratégica de la comunicación financiera un arma estratégica y táctica que permite generar y difundir una imagen frente a un público objetivo (Bompoint y Marois, 2004).

\section{Figura 7}

\section{Análisis de la comunicación financiera, caso Codelco, Chile}

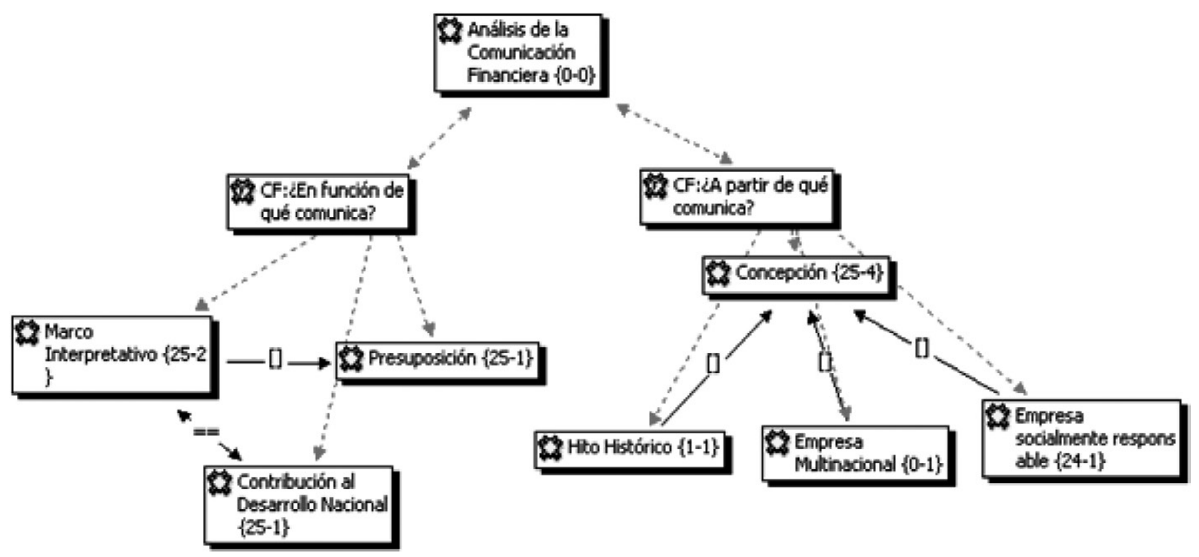

Elaboración propia a partir de resultados obtenidos en la investigación.

Para el caso de la empresa CMPC, los directivos comunican, en primer lugar, a partir de la concepción que ellos tienen de una empresa socialmente responsable y luego a partir del concepto de empresa multinacional. La presuposiciones emitidas se enmarcan principalmente en la dimensión económica (30\%), luego en la dimensión ambiental (18\%) y por último en la dimensión de recursos humanos $(12 \%)$ (ver figura 8$)$.

La alusión al concepto de empresa socialmente responsable aparece, preferentemente, en alusión a la contribución que realiza la empresa a las comunidades que habitan en la proximidad de los espacios en donde dicha empresa realiza sus operaciones; se trata principalmente de comunidades agrícolas, mayoritariamente mapuches (ver figura 8).

En las cartas se encuentran frases tales como "en Chile la fundación CMPC colaboró activamente con la educación de las comunidades [...] la educación de nuestros vecinos ha pasado a constituir un imperativo moral y estratégico" (CMPC, 2009). CMPC es una empresa perteneciente a la industria forestal y como tal sus direc- 
tivos conocen las externalidades que genera su actividad en el entorno, partiendo del aprovisionamiento de materias primas. Para ello es necesario la forestación de territorios que originalmente eran usados en la producción agrícola; paralelamente, la forestación y posterior tala de bosques genera impacto en los pequeños cultivos de comunidades vecinas, por ejemplo, luego de unos años de una plantación forestal los caudales de agua comienzan a disminuir debido a un aumento de la tasa evapotranspirativa (Huber et al., 2010). La defensa de dichos territorios es realizada por grupos de presión social (ambientalistas, indígenas), en tanto que los directivos de CMPC a través de las cartas explicitan información a la comunidad nacional, frente a la presión de dichos grupo de poder social.

En segundo lugar, los directivos comunican a partir de la concepción de empresa multinacional, a diferencia de la empresa Codelco, en donde no se sabe si la empresa posee filiales en el extranjero (ver figura 8). En las cartas de CPMC se puede leer juicios tales como "las filiales en el extranjero mejoran sus resultados medidos en dólares" (CMPC, 2005). "Durante el 2007 se lograron importantes avances en los proyectos de desarrollo internacional de CMPC Tissue, al concretarse la adquisición de las operaciones del grupo mexicano PIMABE" (CMPC, 2007). En ambos casos, los directivos de CMPC comunican que el desempeño de la empresa ha trascendido las fronteras, principalmente a Latinoamérica. Dicha información va dirigida a los accionistas y posibles inversionistas de la empresa (ver figura 8).

Los directivos de la empresa CMPC también suponen la contribución al desarrollo nacional a partir de un rol de empresa socialmente responsable. Se infiere la dimensión estratégica de la comunicación financiera buscando la mimetización con los desafíos que se plantean en su entorno cercano, a diferencia de la empresa Codelco (Lemoine y Onnée, 2003).

La comunicación financiera de CMPC también enfatiza la noción de empresa multinacional y el éxito de proyectos de inversión fuera de las fronteras nacionales. En este sentido, se relaciona la dimensión de marketing de la comunicación financiera con el posicionamiento de la empresa en la bolsa, lo que busca influir positivamente en el precio de la acción de la compañía (Bompoint y Marois, 2004). 
Figura 8

Análisis de la comunicación financiera, caso CMPC

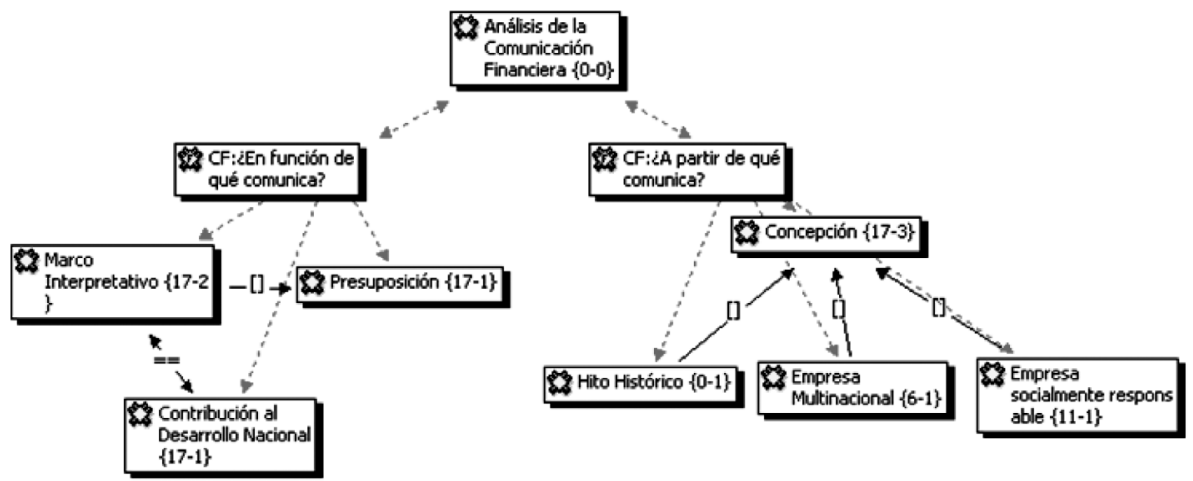

Elaboración propia a partir de resultados obtenidos en la investigación.

\section{Función de la comunicación financiera}

Del análisis de los datos se infiere que el objetivo del discurso expuesto en las cartas de presentación de los estados financieros - emitidas por los directivos de Codelco - es en primer lugar la proyección y mantenimiento de una imagen deseada de los ejecutivos: "Las históricas cifras de estos años - excedentes superiores a US\$ 10.000 millones en el período- [...] reafirman que CODELCO es el mejor negocio con que cuenta Chile [...] CODELCO es la empresa más valorada por todos los ciudadanos" (Codelco, 2005); en segundo lugar, mantener las relaciones de poder con los grupos de presión, especialmente con los trabajadores, lo que se ve reflejado a través de todo el periodo en estudio con juicios como "unas palabras de agradecimientos para los trabajadores de CODELCO, por su compromiso y desarrollo de la empresa, ya que nada de los recursos generados para Chile en estos años de bonanza del precio del cobre habría sido posible sin su participación" (Codelco, 2008) (ver figura 9).

Los trabajadores a través de sus organizaciones sindicales representan uno de los más importantes grupos de presión social. Para ellos, la información financiera de la empresa juega un rol fundamental al momento de llevar a cabo los procesos de negociación colectiva. Se puede inferir que los directivos centran su atención en la conservación de relaciones armónicas con los trabajadores con el objetivo de disminuir el impacto financiero de las demandas colectivas de los trabajadores, de la tasa de accidentabilidad y de las posibles paralizaciones de faenas. 


\section{Figura 9}

\section{Función de la comunicación financiera, caso Codelco}

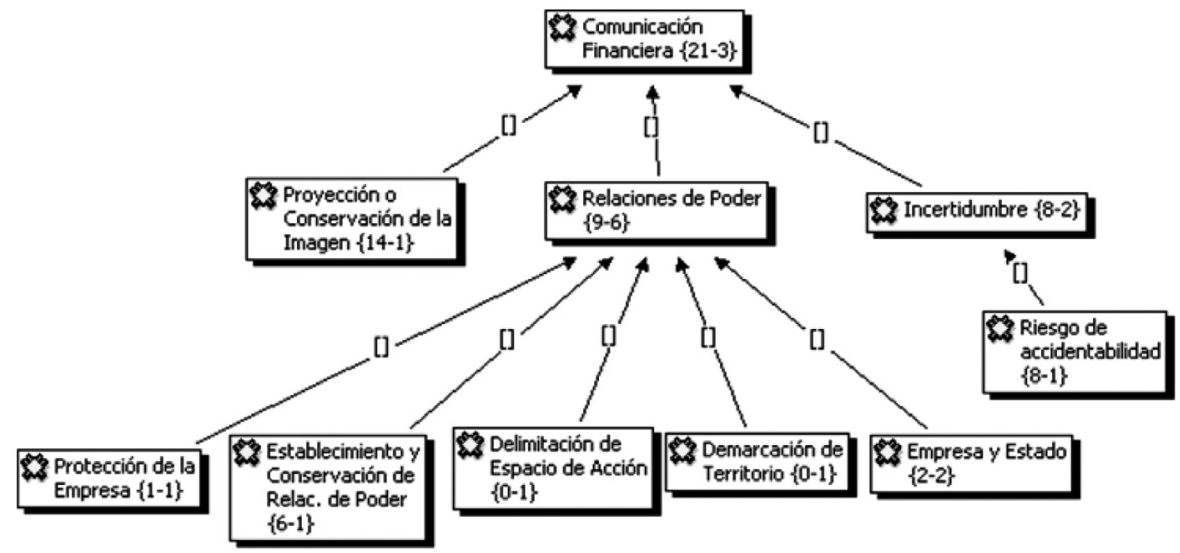

Elaboración propia a partir de resultados obtenidos en la investigación.

Para el caso CMPC la proyección y/o conservación de una imagen deseada se transforma en una constante durante todo el periodo en estudio, por ejemplo, se puede leer: "Las bases de nuestro negocio son sólidas y estamos optimistas de mantener esta senda de desarrollo con una estrategia de inversión focalizada" (CMPC, 2005). Dicha imagen se proyecta principalmente a los accionistas, buscando mantener los niveles de confianza en el grupo económico y, por ende, promocionar a la empresa como un producto, cuyo valor se ve reflejado en el precio de la acción.

Asimismo, es reiterativo el mensaje que pretende comunicar su compromiso con la sociedad chilena en su conjunto, principalmente con los grupos de presión social. Se muestra información sobre los proyectos de responsabilidad social realizados, por ejemplo, "El año 2005 estuvo marcado por la celebración del aniversario número 85 de la empresa, lo que dio origen a diversas actividades con la comunidad [...]. Entre éstas, se destaca la exposición «Lágrimas de Luna», Tesoros de la Platería Mapuche, patrocinada por CMPC [...] consideramos esta muestra como una iniciativa trascendente y un testimonio vivo del respeto que tenemos por la identidad y el legado espiritual de la cultura mapuche" (CMPC, 2005) (ver figura 10).

Indudablemente, dicha información no va dirigida al pueblo mapuche, sino a los accionistas, principalmente, y a grupos de presión social (ambientalistas y pueblos 
originarios), ambos interesados en conocer la relación entre la empresa y su entorno cercano, según los propios intereses de cada grupo.

\section{Figura 10}

\section{Función de la comunicación financiera, caso CMPC}

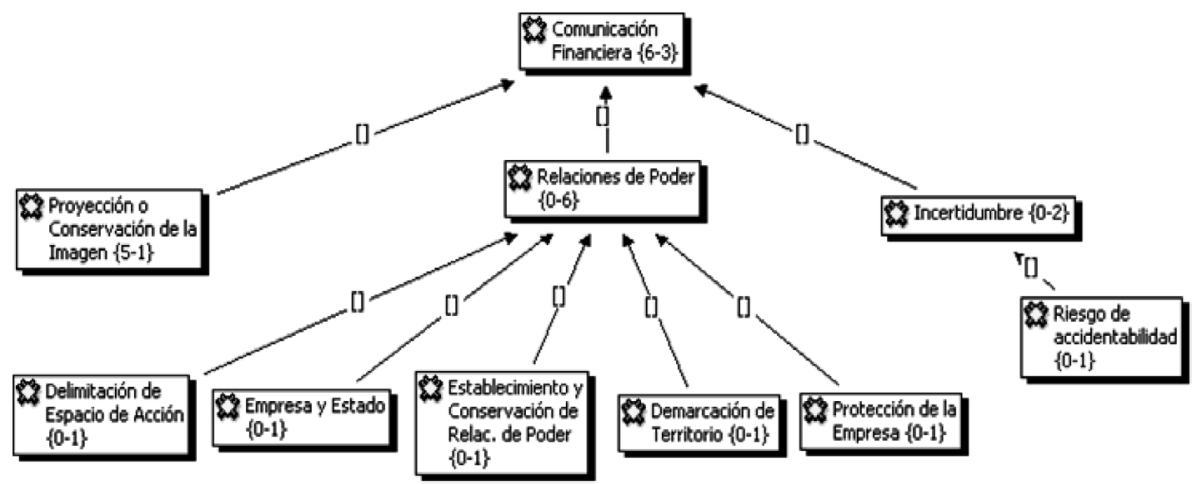

Elaboración propia a partir de resultados obtenidos en la investigación.

\section{Conclusiones}

Del análisis inductivo de los resultados obtenidos, podemos inferir y plantear las siguientes hipótesis: Desde el punto de vista discursivo, los enunciadores de las cartas de comunicación de los estados financieros de ambas empresas se comunican asertivamente con sus destinatarios, involucrándose y comprometiéndolos con el discurso expresado. Desde el punto de vista social, los locutores de las cartas de presentación de los estados financieros de la empresa Codelco establecen en la comunicación relaciones de poder simétricas; por el contrario, para el caso de la empresa CMPC se establecen relaciones asimétricas.

A través del discurso expuesto por el presidente de directorio y/o gerente general en las cartas de presentación de los estados financieros, se busca alinear los resultados obtenidos con el contexto que enfrenta la empresa. El discurso se mimetiza con las situaciones enfrentadas tanto en el país como en el extranjero, las cuales afectaron directa o indirectamente a la empresa. Así, se confirma la articulación entre el texto y el espacio social en dónde éste es producido.

Los directivos - a través de las cartas de presentación de los estados financierosesperan difundir una imagen organizacional deseada a un público específico, así 
como también ejercer influencia sobre los grupos de presión social. Para los directivos de Codelco, el foco de atención se centra en los trabajadores, mientras que para CMPC en las comunidades vecinas. De esta forma se establece la dimensión estratégica del discurso directivo. Por otra parte, para los directivos de CMPC el foco de atención también se centra en los inversionistas, a quienes entregan información financiera de la empresa que influye en el precio de la acción; es decir, la promoción de la empresa como producto frente al mercado bursátil. Así, se establece la dimensión de marketing del discurso directivo, lo que parece delicado, sobre todo en el contexto de las empresas privadas.

El objetivo final de una empresa privada, normalmente, es expresado en términos de maximización de utilidad, lo que muchas veces hace que sus directivos se alejen de lo esencial, es decir, de los procesos productivos; ellos han transformado las empresas en "productos" que se transan en la Bolsa de Valores. Para los directivos lo importante es cómo influir en el precio de la acción, lo anterior los ha alejado de los problemas que ocurren en el núcleo operacional, que es lo que realmente interesa a la sociedad en su conjunto

Finalmente, se puede inferir que uno de los roles de los directivos de las organizaciones - públicas o privadas - es ejercer influencia, a través del lenguaje, sobre un grupo de referencia determinado. Dicha influencia obedece a una estrategia tendiente a posicionar los intereses de las organizaciones representadas. Es así que a través del discurso expuesto en las cartas se pretende ejercer influencia sobre el pensamiento de los receptores, en la construcción de su conocimiento, acumulando experiencias, permitiendo a la vez reiterar sus experiencias, reconociéndolas como idénticas para, finalmente, familiarizarnos con un mundo preformado.

\section{Referencias}

Austin, J.L. (1970). Quand dire, c'est faire. Paris: Seuil.

Alvear, S. (2011). Fonction sociale des activités de qualification. En J.M. Barbier, C. Chauvigné y M.L. Vitali, coords. Diriger: Un travail. Paris: L'Harmattan: 147-160.

Berger, P. y T. Luckmann (1967). The social construction of reality: A treaatise in the sociology of knowledge. New York : Anchor Books. 
Bompoint, P. y B. Marois (2005). Gouvernement d'entreprise et communication financière. Paris: Economica.

Bruner, J. (1986). Actual minds, possible worlds. Cambridge: Harvard University Press. (Existe traducción al español. Realidad mental y mundos posibles. Barcelona: Gedisa, 1988).

(1991). Acts of meaning. Cambridge: Harvard University Press. (Existe traducción al español. Actos de significado: Más allá de la revolución cognitiva. Madrid: Alianza, 1995).

(2002). Making stories: Law, literature, life. New York: Farrar, Strauss and Giroux. (Existe traducción al español. La fábrica de historias. Derecho, literatura, vida. Argentina: Fondo de Cultura Económica, 2003).

Castelló, M., M. Corcelles, A. Iñesta, G. Bañales y N. Vega (2011). La voz del autor en la escritura académica: Una propuesta para su análisis. Signos 44 (76): 105-117.

Charaudeau, P. (1982). Eléments de sémiolinguistique d'une théorie du langage à une analyse du discours. Langage en situation : Pratique sociales et interaction (38): 6-28.

y D. Maingueneau (2002). Dictionnaire d'analyse du discours. Paris: Editions du Seuil. (Existe traducción al español. Diccionario de análisis del discurso. Traducción de: Irene Agoff. Madrid: Amorrortu Editores).

Chekkar, R. y S. Onnée (2006). Les discours managériaux dans le processus de communication financière : Une analyse longitudinale du cas Saint-Gobain. Entreprises et Histoire (42): 46.

Compañía Manufacturera de Papeles y Cartones. Memorias Financieras. Cartas de presentación de los estados financieros. Disponible en http://www.cmpc.cl/ inversionistas/reportes-financieros/reportes-anuales/memorias-financieras.

Corporación Nacional del Cobre. Memorias Financieras. Cartas de presentación de los estados financieros. Disponible en http://www.CODELCO.com/CODELCO-en-numeros/prontus_CODELCO/2012-08-01/153125.html.. 
Ducrot, O. (1984). Le dire et le dit. Paris: Editions de Minuit.

(1991). Dire et ne pas dire. Paris: Hermann.

El-Meligi, M. (2007). Diriger: Une vision humaniste du leadership. Québec: Les Presses de l'Université Laval.

Gadamer, H-G. (1998). Verdad y Método II. Salamanca: Ediciones Sígueme.

Giroux, N. y L. Marroquin (2005). L'approche narrative des organisations. Revue Française de Gestion 6 (159): 15-42.

Gómez, O., B. De La Hoz y M. López (2011). Valor razonable como método de medición de la información financiera. Revista Venezolana de Gerencia 16 (56): 608-621.

Huber, A., A. Iroumé, C. Mohr y C. Frêne (2010). Efectos de plantaciones de Pinus Radiata y Eucalyptus globulus sobre el recurso agua en la cordillera de la costa de la región del Biobío, Chile. Bosque 31 (3): 219-230. Disponible también en www.scielo.cl.

Ibáñez, R. (2012). La comprensión del discurso escrito: Una propuesta teórica-metodológica para su evaluación. Signos 45 (78): 20-43. Disponible también en www.scielo.cl.

Kerbrat-Orecchioni, C. (1980). L'énonciation de la subjectivité dans le langage. Paris : Colin.

Lemoine, J.-F. y S. Onnée (2003). Vers une analyse des enjeux et des pratiques de la gestion de la relation avec l'actionnaire individuel. Décisions Marketing (31): 25-37.

Pilleux, M. (2001). Competencia comunicativa y análisis del discurso. Revista Estudios Filológicos (36): 143-152. Disponible también en www.scielo.cl

Rivière, A. (2006). Le discours organisationnel vu par les sciences de gestion : monologue, polyphonie ou cacophonie? Entreprise et Histoire 42: 29-45. 
Seignour, A. (2011). Méthode d'analyse des discours. L'exemple de l'allocution d'un dirigeant d'entreprise publique. Revue Française de Gestion 2 (211): 29-45.

Watzlawick, P., J. Beavin y D. Jacksondon (1972). Une logique de la communication. Paris: Seuil.

Weick, K. (1995). Sensemaking in Organizations. California: Sage Publications. 
